\title{
Evaluation of hyperketonemia risk period and screening protocols for early-lactation dairy cows
}

\author{
A. Mahrt, O. Burfeind, and W. Heuwieser ${ }^{1}$ \\ Clinic for Animal Reproduction, Faculty of Veterinary Medicine, Freie Universität Berlin, Königsweg 65, 14163 Berlin, Germany
}

\begin{abstract}
The objectives of this study were to describe the onset of hyperketonemia, the number of positive hyperketonemia test results, and the duration of the longest hyperketonemic period during the first $42 \mathrm{~d}$ in milk (DIM) in dairy cows. Furthermore, we set out to evaluate test characteristics of single and repeated measurements of $\beta$-hydroxybutyric acid (BHBA) during this period to diagnose hyperketonemia. Using an electronic handheld meter, 252 cows from 3 farms were tested twice weekly for hyperketonemia (blood BHBA $\geq 1.2 \mathrm{mmol} / \mathrm{L}$ ) during the first $42 \mathrm{DIM}$, resulting in 12 test results per cow (i.e., in lactation wk 0.5 to $6)$. Prevalence and incidence of hyperketonemia were calculated for the 12 examination days and the 42-d period, respectively. Test characteristics for the diagnosis of hyperketonemia were calculated for 4 different testing scenarios (testing all cows 1, 2, 3, or 6 times during the first 42 DIM) and 2 different gold-standard definitions $(\mathrm{BHBA} \geq 1.2 \mathrm{mmol} / \mathrm{L}$ at least once during the observation period or $\mathrm{BHBA} \geq 1.2 \mathrm{mmol} / \mathrm{L}$ at least twice during the observation period). Mean prevalence of hyperketonemia was $11.8 \%$, ranging from $9.6 \%$ in lactation wk 0.5 and 2.0 to $14.6 \%$ in lactation wk 5.5. In total, 134 cows $(53.2 \%)$ had at least 1 positive hyperketonemia test result during the whole 42 -d period. Of these cows, $46.3 \%$ had only 1 positive result. The median first positive hyperketonemia test result was in lactation wk 2.0 [interquartile range (IQR) 1.0-3.5]. Median frequency of positive test results in cows affected by hyperketonemia was 2 positive test results (IQR 1-3). Median duration of the longest hyperketonemic period per cow affected was 1 examination interval (3-4 d; IQR 1-2). Considering a minimum of 1 positive hyperketonemia test result during the first 42 DIM as the gold standard, sensitivity of a single BHBA measurement during this period to diagnose hyperketonemia was $21 \%$. A weekly testing protocol had a sensitivity of $72 \%$. Specificity was $100 \%$ in both
\end{abstract}

Received September 29, 2014.

Accepted January 30, 2015.

${ }^{1}$ Corresponding author: w.heuwieser@fu-berlin.de cases. Considering a minimum of 2 positive hyperketonemia test results as the gold standard, sensitivity and specificity of a single BHBA measurement during the first 42 DIM were 33 and 97\%, respectively. A weekly testing protocol provided sensitivity and specificity of 91 and $83 \%$, respectively. We conclude that the risk period for hyperketonemia lasts at least until lactation wk 6 , which should be considered when planning hyperketonemia screening programs. Test characteristics of screening protocols depend on testing frequency.

Key words: hyperketonemia, screening, $\beta$-hydroxybutyric acid (BHBA), testing frequency, ketosis

\section{INTRODUCTION}

Hyperketonemia is a common condition in lactating dairy cows (Duffield et al., 2009; McArt et al., 2012a; Suthar et al., 2013). Usually developing during the early postpartum period, hyperketonemia negatively affects milk yield (Ospina et al., 2010) and reproductive performance (Walsh et al., 2007a,b) and increases the risk of subsequent diseases. Different studies have found relationships between hyperketonemia and the occurrence of clinical ketosis, displaced abomasum, metritis, and lameness (LeBlanc et al., 2005; Duffield et al., 2009; Suthar et al., 2013). Roberts et al. (2012) found an increased risk of culling in cows with elevated serum BHBA concentrations during late gestation and early lactation. The main factor leading to hyperketonemia under modern husbandry conditions is a maladaptation to the negative energy balance that affects almost every dairy cow around parturition (Herdt, 2000).

According to the absence of clinical signs in cases of subclinical ketosis (Andersson, 1988), diagnosis of this common type of hyperketonemia depends solely on the measurement of ketone body concentrations in blood, milk, or urine. The gold-standard test is measurement of the blood BHBA concentration in laboratories (Oetzel, 2004); however, electronic handheld blood BHBA meters have been evaluated, providing practical and time-related benefits (Iwersen et al., 2009, 2013; Mahrt et al., 2014b). An established blood BHBA cutpoint for hyperketonemia is $1.2 \mathrm{mmol} / \mathrm{L}$ (Duffield et al., 1998; 
Enjalbert et al., 2001; Suthar et al., 2013). Strategic programs for monitoring dairy herds for hyperketonemia have been recommended (Duffield, 2000; Oetzel, 2004; LeBlanc et al., 2005; Ospina et al., 2013). However, screening dairy cows for hyperketonemia requires information on appropriate sampling time and frequency. The first 14 to $16 \mathrm{~d}$ after parturition have been described as the main risk period for hyperketonemia (Duffield et al., 1998; McArt et al., 2012a), whereas longer risk periods have been mentioned by Andersson (1988), Dohoo and Martin (1984), Oetzel (2004), and Holtenius and Holtenius (1996). To our knowledge, there is a lack of science-based information on the time of beginning and duration of hyperketonemia in early-lactation dairy cows under modern husbandry and feeding conditions monitored over a longer period. Moreover, the test characteristics of different testing protocols to diagnose hyperketonemia during a longer period have not yet been evaluated. Therefore, the objectives of our study were (1) to describe the time of the first positive hyperketonemia test (blood BHBA $\geq 1.2 \mathrm{mmol} / \mathrm{L}$ ), and (2) to determine the number of positive hyperketonemia tests and the duration of the longest hyperketonemic period in untreated dairy cows tested frequently during the first 42 DIM. Finally, we set out (3) to determine test characteristics (sensitivity, specificity, positive and negative predictive values) of a single BHBA measurement during this time interval to diagnose hyperketonemia and evaluate whether these test characteristics could be enhanced by repeating measurements after certain time intervals. We hypothesized that hyperketonemia in dairy cows under modern husbandry and feeding conditions occurs until at least 42 DIM. We furthermore hypothesized that test characteristics of hyperketonemia testing protocols improve with the number of measurements during the first 42 DIM.

\section{MATERIALS AND METHODS}

\section{Experimental Design}

In total, 305 first-lactating and multiparous dairy cows from 3 commercial dairy farms in Brandenburg and Sachsen-Anhalt, Germany, were included in the trial. All farms kept at least 600 Holstein-Friesian dairy cows in freestall barns, fed a TMR, and recorded medical treatments using computer-based farm management programs. Farm 1 kept approximately 1,200 cows in a freestall barn with slatted floors and cubicles equipped with rubber mats. Cows were fed a TMR consisting of $36 \%$ corn silage, $37.6 \%$ concentrate mineral mix, $23.5 \%$ grass silage, and $3 \%$ rape straw on a DM basis $\left(\mathrm{NE}_{\mathrm{L}}=\right.$ $7.21 \mathrm{MJ} / \mathrm{kg}$ of DM). This TMR included $400 \mathrm{~g}$ of glyc- erol per cow and day. Feed was delivered over a conveyer belt system 10 times per day. Cows were milked 3 times a day in a 52-stall rotary milking parlor. The average annual milk yield was 10,733 kg (ECM). Farm 2 kept approximately 1,800 cows in a freestall barn with slatted floors and cubicles equipped with rubber mats. Cows were fed a TMR consisting of $41.2 \%$ corn silage, $32.1 \%$ concentrate mineral mix, $24.2 \%$ grass silage, and $2.7 \%$ wheat straw on a DM basis $\left(\mathrm{NE}_{\mathrm{L}}=7.05 \mathrm{MJ} / \mathrm{kg}\right.$ of DM). This TMR included $300 \mathrm{~g}$ of glycerol per cow and day. Feed was delivered over a conveyer belt system 8 times per day. Cows were milked 3 times a day in a 68 -stall side-by-side milking parlor. The average annual milk yield was 10,900 kg (ECM). Farm $3 \mathrm{kept}$ approximately 600 cows in a freestall barn with concrete solid floors and cubicles with a straw-chalk mix. For the first 21 DIM, cows received a TMR consisting of $26.2 \%$ corn silage, $45 \%$ concentrate mineral mix, $24 \%$ grass silage, and $5 \%$ straw on a DM basis $\left(\mathrm{NE}_{\mathrm{L}}=6.99 \mathrm{MJ} / \mathrm{kg}\right.$ of $\mathrm{DM})$. This TMR included $300 \mathrm{~g}$ of propylene glycol. From 22 DIM, cows received a TMR consisting of $24 \%$ corn silage, $48.7 \%$ concentrate mineral mix, $24 \%$ grass silage, and $3.3 \%$ straw on a DM basis $\left(\mathrm{NE}_{\mathrm{L}}=6.94 \mathrm{MJ} /\right.$ $\mathrm{kg}$ of DM). Feed was delivered once daily and pushed up 3 times a day, ensuring that cows had continuous access to feed. Cows were milked 2 times a day in a 24-stall herringbone parlor, and the average annual milk yield was 11,127 kg (ECM).

All experimental procedures reported herein were conducted with the approval of the Institutional Animal Care and Use Committee of Freie Universität Berlin. The trial was conducted between June and December 2013. Cows were enrolled between 1 and 4 DIM and were tested for hyperketonemia twice weekly at intervals of 3 to $4 \mathrm{~d}$ for an examination period of $42 \mathrm{~d}$, resulting in 12 test results per cow. The term "lactation week" was used to describe the time of sample collection relative to calving (e.g., lactation wk 0.5 for the first measurement on DIM 1 to 4, lactation wk 1 for the second measurement on DIM 4 to 7 , lactation wk 1.5 for the third measurement on DIM 8 to 11).

Measurement of BHBA was conducted using an electronic BHBA meter (NovaVet, Nova Biomedical, Waltham, MA) recently validated for the use in dairy cows (Mahrt et al., 2014b), providing a sensitivity of $97 \%$ and a specificity of $82 \%$ for the diagnosis of hyperketonemia using a cutpoint of $1.2 \mathrm{mmol} / \mathrm{L}$ BHBA. The test system includes the handheld device and test strips, which are equipped with an electrochemical reaction field at the tip. Blood samples were collected from the tail vessels using a 2-mL syringe (Henry Schein Inc., Melville, NY) and a 23-gauge needle (Sterican, B. Braun, Melsungen, Germany). Blood was analyzed immediately after sampling by applying a small amount of 
blood from the syringe to the test strip of the electronic BHBA meter. Results were displayed in millimoles per liter and recorded. Concentrations $\geq 1.2 \mathrm{mmol} / \mathrm{L}$ were considered positive. Cows that showed signs of clinical ketosis (reduced feed intake, reduced milk production, or both in absence of other clinical symptoms, e.g., fever) identified by the farm personnel were treated by farm personnel according to the farm veterinarian's recommendations. Treatments were recorded and included intravenous applications of a butafosfan-cyanocobalamin combination (Catosal, Bayer Animal Health, Leverkusen, Germany), dextrose or dexamethasone (Dexatat ad us.vet., aniMedica, Senden-Bösensell, Germany) as well as oral administration of propylene glycol, or combinations of these therapies. Cows treated with one or more of these drugs after the day of parturition were excluded from analysis, because effects on blood BHBA concentrations are possible (Gordon et al., 2013). Cows treated with one or more of these drugs for indications other than clinical ketosis were likewise excluded from analysis. Nineteen cows were treated after the day of parturition. Of the cows treated, 9 were treated because of symptoms of clinical ketosis, whereas the remainder received the treatment due to other indications. On farms 1 and 2, cows in the third or greater lactation routinely received a combination prophylaxis against disorders of calcium and energy metabolism, containing intravenous administrations of dextrose (160 g per cow) or dexamethasone $(0.04 \mathrm{mg} / \mathrm{kg}$ of BW, off-label use). This prophylaxis was administered immediately after parturition at 0 DIM. Cows that received the prophylaxis were not excluded from analysis. On farm 1, cows were offered an oral nutritional supplement containing dextrose immediately after parturition at 0 DIM. These cows were also not excluded from analysis. A total of 34 cows had fewer than 11 BHBA test results and were excluded from analysis. After exclusion, 252 cows (parity $2.6 \pm 1.3$ ) were used for analysis. Of these cows, 102 were from farm 1, 96 were from farm 2, and 54 were from farm 3 .

\section{Statistical Analysis}

All data were statistically analyzed with SPSS (version 22.0, IBM Deutschland GmbH, Ehningen, Germany). The distribution of parities $(1,2, \geq 3)$ between the 3 farms was tested using a $\chi^{2}$ test. Hyperketonemia was defined as a blood BHBA concentration $\geq 1.2 \mathrm{mmol} / \mathrm{L}$. Prevalence of hyperketonemia was calculated for each of the 12 examination days by dividing the number of cows with hyperketonemia by the total number of cows tested on a given examination day. Prevalence was also averaged for the whole 42-d period. Distribution of prevalence between the 3 farms was tested using a $\chi^{2}$ test. Incidence of hyperketonemia was calculated for every examination interval by dividing the number of cows that first tested positive for hyperketonemia by the total number of cows at risk on that given examination day. Furthermore, incidence was calculated for the whole 42-d period. Cows at risk were all cows with recorded test results that did not test positive for hyperketonemia earlier on that specific examination day. Survival analysis for the risk of hyperketonemia within the experimental period was performed using Cox regression. Therefore, farm $(1,2,3)$ and parity class $(1=$ first parity, $2=$ second parity, $3=$ third or greater parity) were included as factors in the model. Farm 1 and first parity were chosen as references. Hazard ratios, $95 \%$ confidence intervals, and $P$-values are reported. Kaplan-Meier curves were generated to visualize the effects of farm and parity. Median duration of hyperketonemia was compared between farms and between parity classes using a Kruskal-Wallis test. Post hoc pairwise comparisons between the farms were performed with Mann-Whitney U-tests.

Test characteristics for the diagnosis of hyperketonemia were calculated for 4 different scenarios (scenario $\mathbf{T 1}=$ testing all cows once between 1 and 42 DIM; scenario $\mathbf{T} \mathbf{2}=$ testing all cows twice, once between 1 and 21 DIM and once between 22 and 42 DIM; scenario T3 $=$ testing all cows 3 times, once between 1 and 14 DIM, once between 15 and 28 DIM, and once between 29 and 42 DIM; and scenario T6 = testing all cows 6 times, once between 1 and 7 DIM, once between 8 and 14 DIM, once between 15 and 21 DIM, once between 22 and 28 DIM, once between 29 and 35 DIM, and once between 36 and 42 DIM). For each of these scenarios, 2 gold-standard definitions $(\mathbf{G} \mathbf{1}=\mathrm{BHBA} \geq 1.2$ $\mathrm{mmol} / \mathrm{L}$ at least once during the observation period; G2 $=$ BHBA $\geq 1.2 \mathrm{mmol} / \mathrm{L}$ at least twice during the observation period) were considered. Sensitivity was calculated as the proportion of cows correctly diagnosed with hyperketonemia in a given scenario of all cows that were truly suffering from hyperketonemia. Specificity was calculated as the proportion of cows correctly diagnosed as nonhyperketonemic in a given scenario of all cows that were truly nonhyperketonemic. The positive predictive value was determined as the proportion of cows diagnosed with hyperketonemia in a given scenario that were truly suffering from hyperketonemia. The negative predictive value was determined as the proportion of cows diagnosed as nonhyperketonemic in a given scenario of all cows that were truly nonhyperketonemic. The testing scenarios were chosen to imitate different practical approaches of screening programs for hyperketonemia on dairy farms. Every 


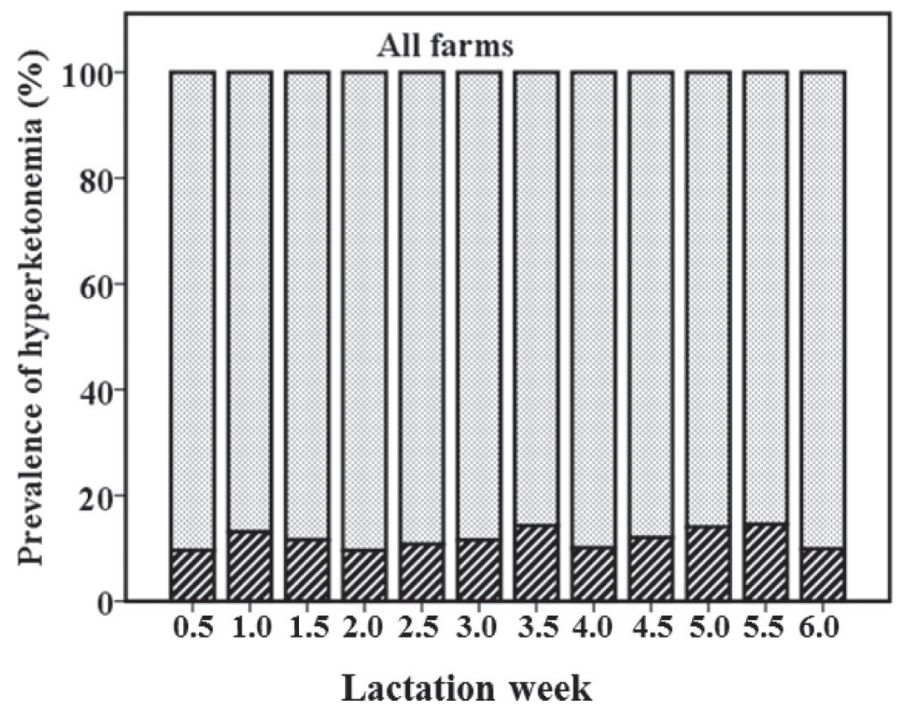

Figure 1. Overall prevalence of hyperketonemia (hatched areas) during the first $6 \mathrm{wk}$ of lactation.

cow in the analysis had at least 11 measurements taken between 1 and 42 DIM. However, when implementing the 4 different testing scenarios in practice, every cow would have been measured only 1, 2, 3, or 6 times during the examination period. Therefore, the measurements taken for analysis were randomly chosen using the random number generator in SPSS. For example, in scenario 1 , only 1 of the 12 measurements between 1 and 42 DIM was randomly chosen for analysis. In the scenarios with multiple measurements, the first measurement was randomly chosen from the specific period. The next measurement was chosen based on the frequency of testing scheme (i.e., $7 \mathrm{~d}$ later in a weekly testing scenario, $14 \mathrm{~d}$ later in a 2 -wk testing scenario, $21 \mathrm{~d}$ later in a 3 -wk testing scenario). To minimize error by chance due to the random selection process, in each scenario, 20 different repetitions were randomly generated and test characteristics calculated for each of these 20 repetitions. The mean test characteristics and the corresponding $95 \%$ confidence intervals were calculated and reported.

\section{RESULTS}

Of 305 cows enrolled in the trial, $53(17.4 \%)$ were excluded from analysis as described above; 252 cows remained for analysis. Of these cows, $59(23.4 \%)$ were in first lactation, $77(30.6 \%)$ were in second lactation, and $116(46 \%)$ were in the third or greater lactation $(3.8$ $\pm 0.9)$. Proportions of parities differed between farms $(P<0.05)$. The proportion of first-lactation cows was $24.5,18.8$, and $29.6 \%$ on farms 1,2 , and 3 , respectively. A total of $29.4,36.5$, and $22.2 \%$ cows were in second lactation on farms 1,2 , and 3 , respectively. The proportion of cows in third or greater lactation was 46.1, 44.8, and $48.1 \%$ on farms 1,2 , and 3 , respectively.

\section{Prevalence of Hyperketonemia}

Prevalence of hyperketonemia during the examination period is shown in Figure 1. Mean prevalence was $11.8 \%$, ranging from $9.6 \%$ in lactation wk 0.5 and 2.0 to $14.6 \%$ in lactation wk 5.5. Prevalence differed between farms $(P<0.05$; Figure 2$)$. On farm 1 , mean prevalence was $5.8 \%$ and ranged between $2 \%$ (lactation wk 4.0 and 4.5 ) and $8.8 \%$ (lactation wk 1.5). On farm 2, mean prevalence was $9.2 \%$ and ranged between $4.3 \%$ (lactation wk 0.5 and 2.5 ) and $14.9 \%$ (lactation wk 5.0). On farm 3, prevalence was $27.6 \%$ and ranged between $15.9 \%$ (lactation wk 6.0) and 37\% (lactation wk 1.0). Mean prevalence of hyperketonemia in cows in first and second lactations was 7 and $6.6 \%$, respectively, whereas it was $17.6 \%$ in cows in the third or greater lactation.

\section{Incidence of Hyperketonemia}

Incidence of hyperketonemia considering all farms is shown in Figure 3A. In total, 134 cows $(53.2 \%)$ had at least one positive BHBA test result during the whole 42-d period. Incidence of hyperketonemia differed between farm $1(38.2 \%)$, farm $2(51.0 \%)$, and farm 3 (85.2\%) $(P<0.05$; Figure 3B). Consequently, the risk of developing hyperketonemia was 4.19 times higher for cows on farm 3 than for cows on farm $1(P<0.05)$, whereas risk did not differ between cows on farms 1 and $2(P=0.15)$, as calculated with the Cox regression (Table 1).

Incidence of hyperketonemia during the entire $42-\mathrm{d}$ period considering parity was $42.4 \%$ in first-lactation cows. Cows in the second and third or greater lactations had an incidence of 46.8 and $62.9 \%$, respectively. Incidence of hyperketonemia differed between parities $(P<0.05$; Figure $3 \mathrm{C})$ and had a similar distribution considering all farms with the lowest incidence in firstlactation cows and the highest incidence in cows in the third or greater lactation. The risk of developing hyperketonemia was 2.22 times higher for cows in the third or greater lactation compared with cows in the first lactation $(P<0.05)$, whereas risk did not differ between cows in the first and second lactations $(P=$ 0.20 ), as calculated with the Cox regression (Table 1 ).

\section{Time of First Positive BHBA Test Result}

The median first positive hyperketonemia test result was in lactation wk 2.0 [interquartile range (IQR) 1.0 to 3.5]. Stratified by farm, the first positive result oc- 
A

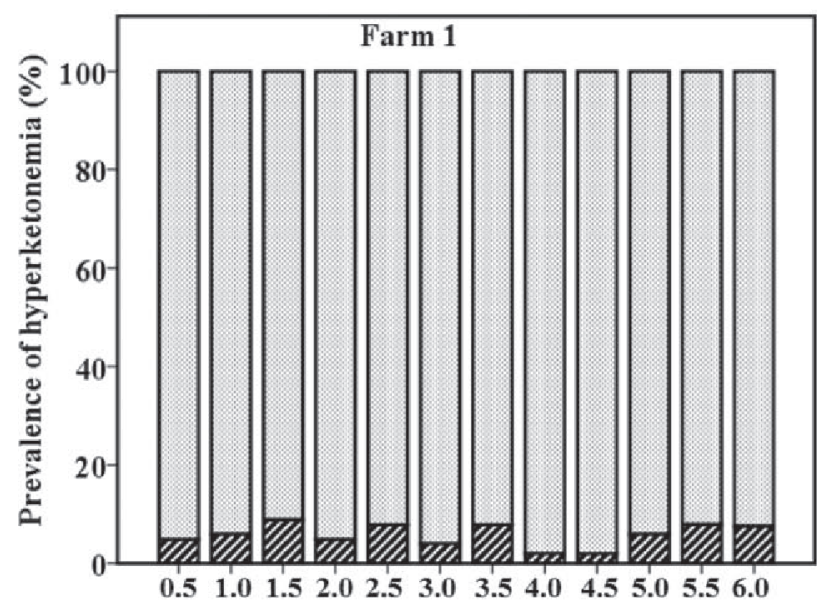

B

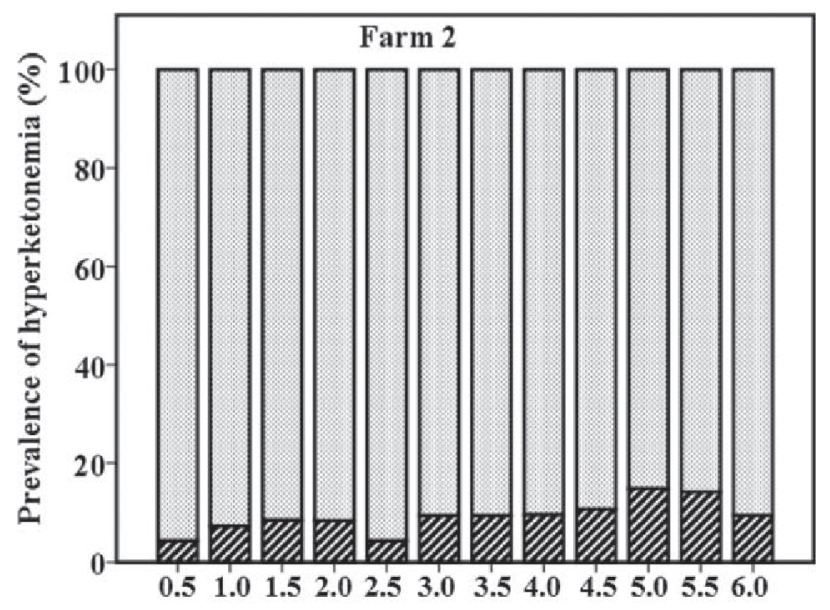

C

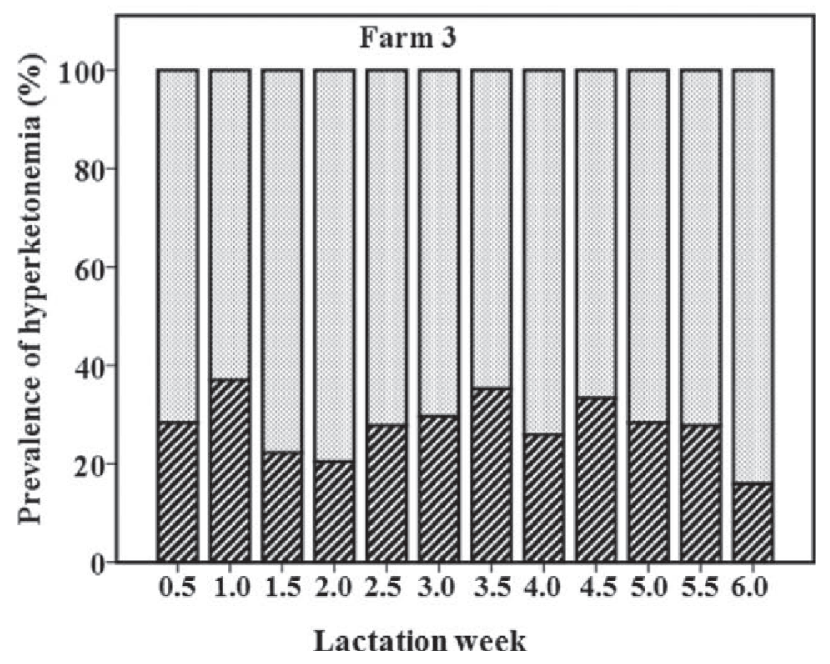

Figure 2. Prevalence of hyperketonemia (hatched areas) on farm 1 (A), farm 2 (B), and farm 3 (C) during the first 6 wk of lactation. curred in lactation wk 2.5, 2.5, and 1.0 (IQR 1.0-3.5, IQR 1.5-4.5, IQR 0.5-3.0) on farms 1,2 , and 3, respectively. First-lactation cows had the median first positive hyperketonemia test result in lactation wk 4.0 (IQR 1.5-5.0). Cows in the second and third or greater lactations had the median first positive test result in lactation wk 2.5 (IQR 1.5-3.5) and in lactation wk 2.0 (IQR 1.0-3.0), respectively.

\section{Number of Positive Test Results}

The frequency distribution of positive hyperketonemia test results is shown in Figure 4. Of all 134 cows with hyperketonemia, 62 cows $(46.3 \%)$ had only 1 positive test result during the first 42 DIM. Median frequency of positive test results in cows affected by hyperketonemia was 2 positive test results (IQR 1-3; Table 2). Stratified by farm, the frequency of positive test results did not differ between farm 1 and farm $2(P$ $=0.61)$, but did differ between farms 1 and 2 and farm $3(P<0.05)$. Stratified by parity, the median frequency of positive hyperketonemia did not differ between firstlactation cows and second-lactation cows $(P=0.26)$ or between first-lactation cows and cows in the third or greater lactation $(P=0.07)$, but did differ between second-lactation cows and cows in the third lactation or greater $(P<0.05)$.

\section{Duration of the Longest Hyperketonemic Period}

Median duration of the longest hyperketonemic period per cow affected was 1 examination interval (3-4 d; IQR 1-2 examination intervals). Duration of the longest hyperketonemic period differed between farms $(P$ $<0.05)$ with a median length of 1 examination interval (IQR 1-1) on farm 1, 1 examination interval (IQR 1-2) on farm 2, and 2 examination intervals (IQR 1-3) on farm 3 .

\section{Test Characteristics of Single and Repeated BHBA Measurements}

Sensitivity, specificity, and positive and negative predictive values for the 4 different testing scenarios under both gold-standard definitions are presented in Table 3 . Testing scenarios G1T1 and G2T1, containing a single BHBA measurement between 1 to 42 DIM, resulted in sensitivities of $21 \%(16-27 \%)$ and $33 \%(23-43 \%)$, respectively. Specificities were $100 \%$ and $97 \%$ (93-100\%), respectively. In contrast, testing scenarios G1T6 and G2T6, representing the most laborious scenarios with weekly BHBA measurements between 1 to 42 DIM, achieved sensitivities of $72 \%(65-79 \%)$ and $91 \%$ (86- 

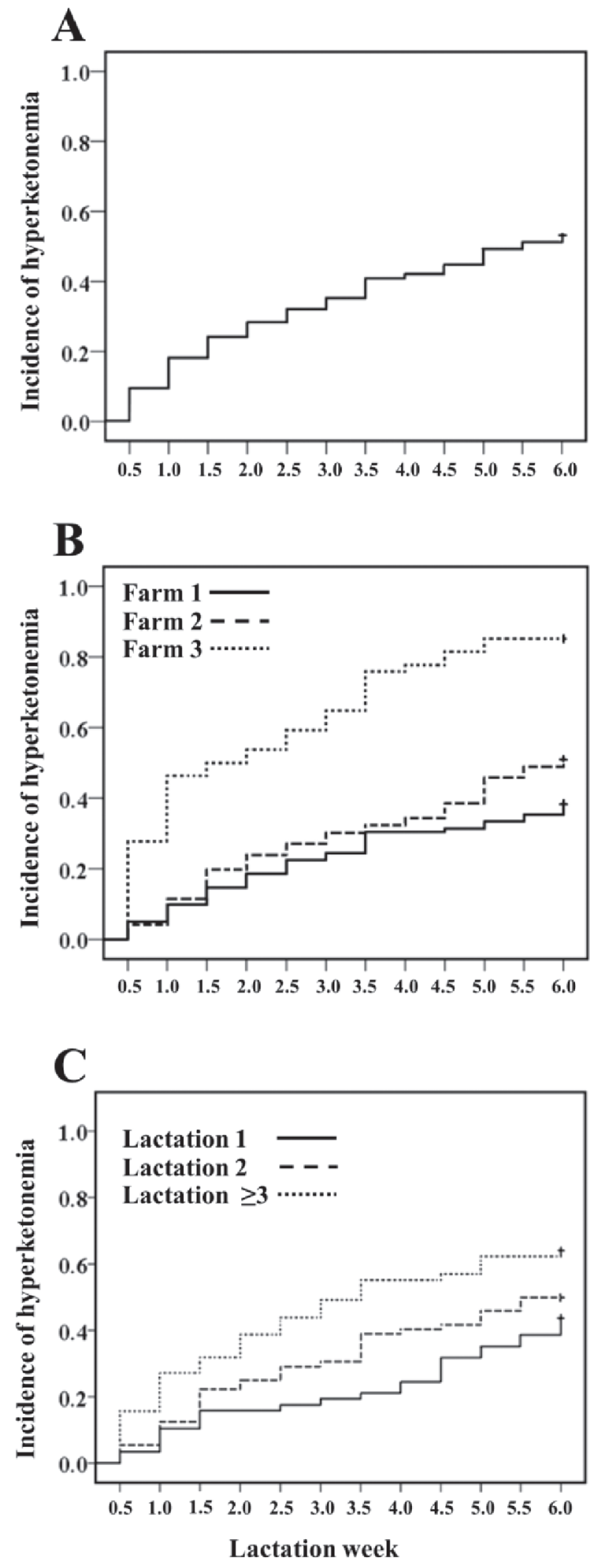

Figure 3. Incidence of cows with hyperketonemia during the first 6 wk of lactation overall (A) and classified by farm (B) and by parity (C).
$95 \%$ ), respectively. Specificities were $100 \%$ and $83 \%$ (78-87\%), respectively.

\section{DISCUSSION}

\section{Epidemiological Parameters}

During this study, mean prevalence of hyperketonemia based on a threshold of $1.2 \mathrm{mmol} / \mathrm{L}$ BHBA was lower than that described for Germany by Suthar et al. (2013), particularly because of the low prevalence on farms 1 and 2. Possible reasons for variations in the prevalence of hyperketonemia between farms are feeding strategies, genetic variation, milk yield, transition cow management practices, other diseases (Ingvartsen, 2006; Oetzel, 2007; Roche et al., 2009; van der Drift et al., 2012), and prevention strategies on the study farms. The scope of our study, however, was not to determine the prevalence of hyperketonemia on a representative sample of farms but to study its long-term occurrence and dynamics. Prevalence was lower in firstand second-lactation cows than in older cows, which is in agreement with findings by Duffield et al. (1998). Electronic handheld meters do not represent the gold standard in measurement of BHBA but, because of practical reasons, are frequently used in hyperketonemia research (McArt et al., 2012a; Shire et al., 2013; Suthar et al., 2013; Denis-Robichaud et al., 2014).

McArt et al. (2013) noted that using the incidence of hyperketonemia has benefits over using its prevalence for the identification of optimal testing and treatment strategies at the group level. Incidence describes the percentage of cows with new cases of hyperketonemia in a group of cows frequently tested during the risk period, whereas prevalence presents the percentage of all affected cows at a certain moment (i.e., a snapshot). Subclinical ketosis lasts, on average, $5 \mathrm{~d}$ (McArt et al., 2012a). Therefore, as implemented in our study, a hyperketonemia testing protocol to estimate group incidence as closely as possible should include at least 2 tests per week (McArt et al., 2013). This protocol, however, requires considerable effort. Several authors have recommended calculating the incidence of hyperketonemia by approximately doubling the average prevalence (Oetzel, 2004; McArt et al., 2013). As the incidence depends on the period examined, however, such a calculation remains an approximation. During our study, the prevalence:incidence ratio was about 4.5 considering all farms and ranged between 3.1 (farm 3) and 6.6 (farm 1).

A median disease duration of $5 \mathrm{~d}$ has recently been described (McArt et al., 2012a), which is slightly longer than the mean duration in our study [median duration $=1$ examination interval; i.e., 3 to $4 \mathrm{~d}$ (IQR 1-2 exami- 
Table 1. Results of the survival analysis (Cox regression) for the odds of developing hyperketonemia within the first 6 wk of lactation

\begin{tabular}{lccc}
\hline & \multicolumn{3}{c}{ Probability of hyperketonemia } \\
\cline { 2 - 4 } Parameter & $\begin{array}{c}\text { Hazard } \\
\text { ratio }\end{array}$ & $95 \%$ CI & $P$-value \\
\hline Farm & & & $<0.05$ \\
Farm 1 & & Reference & \\
Farm 2 & 1.36 & $0.89-2.07$ & 0.15 \\
Farm 3 & 4.19 & $2.71-6.48$ & $<0.05$ \\
Parity class & & & $<0.05$ \\
First lactation & 1.40 & Reference & \\
Second lactation & $0.84-3.52$ & 0.20 \\
Third or greater lactation & 2.22 & $1.40-3.52$ & $<0.05$ \\
\hline
\end{tabular}

nation intervals)]. The cows observed by McArt et al. (2012a), however, were each tested 6 times from 3 to 16 DIM, whereas cows in our study were observed until 42 DIM. The sampling frequency in our study (i.e., twice a week for $6 \mathrm{wk}$ ) did not allow a more precise determination of the duration of hyperketonemia.

Of all cows affected, the majority had only one positive test result and recovered without any treatment. Further research is warranted to determine if these animals have the same risk for subsequent disease, reduced milk yield, and decreased reproductive performance as cows with a longer duration of hyperketonemia.

The study farms showed different patterns of occurrence of hyperketonemia. Several authors have described different types of ketosis (Holtenius and Holtenius, 1996; Oetzel, 2004, 2007). Holtenius and Holtenius (1996) described 2 etiological pathways potentially leading to hyperketonemia. Whereas type I ketosis develops between wk 3 and 6 postpartum mainly in highyielding dairy cows with a consequentially high demand for glucose, type II ketosis occurs earlier in lactation in cows overfed during the dry period and suffering from a disturbed metabolic adaptation to their negative energy balance. Time of occurrence of hyperketonemia, therefore, can be indicative of possible causes (Oetzel, 2004; LeBlanc, 2010). Cows with hyperketonemia type

Table 2. Median frequency (interquartile range in parentheses) of positive hyperketonemia test results within the first $6 \mathrm{wk}$ of lactation

\begin{tabular}{ll}
\hline Parameter & $\begin{array}{c}\text { Positive } \\
\text { result }\end{array}$ \\
\hline Overall & $2(1-3)$ \\
Farm & $1(1-2)$ \\
Farm 1 & $1(1-3)$ \\
Farm 2 & $3(2-5)$ \\
Farm 3 & \\
Parity class & $2(1-3)$ \\
First lactation & $1(1-2)$ \\
Second lactation & $2(1-5)$ \\
Third or greater lactation &
\end{tabular}

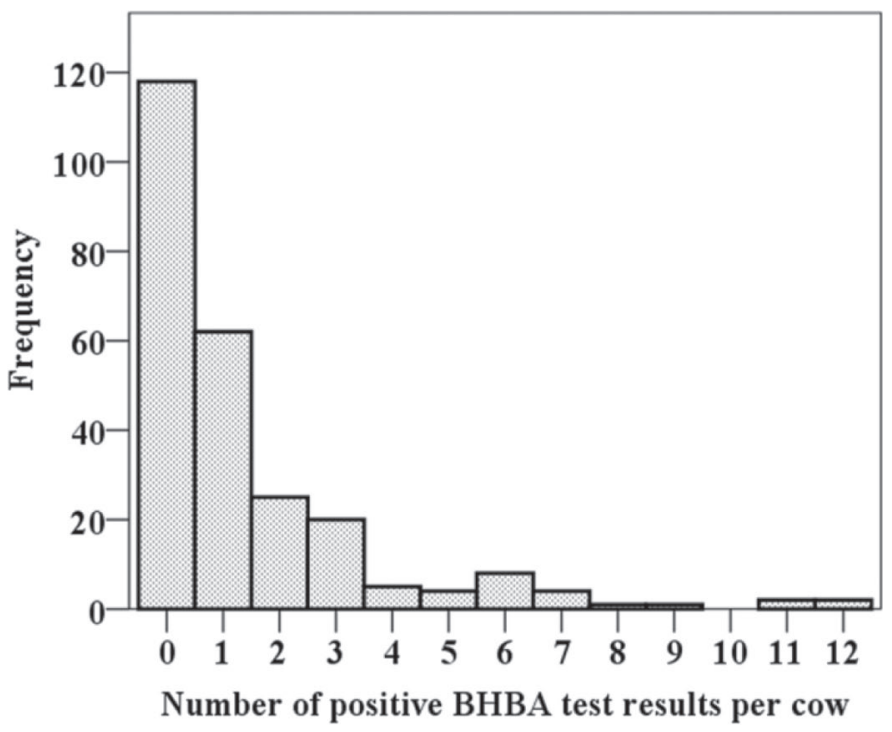

Figure 4. Frequency of positive hyperketonemia test results per cow within the first 6 wk of lactation.

II, however, may remain hyperketonemic until lactation wk 3 or more (Oetzel, 2004) and both types can coexist. Therefore, to optimize hyperketonemia testing protocols, different occurrence patterns should be considered.

\section{Evaluation of Hyperketonemia Screening Protocols}

LeBlanc (2010) outlined the 2 reasons for implementing hyperketonemia monitoring programs in dairy herds: to control the success of management programs at the group or herd level and to identify and treat cows affected or at high risk for disease at the individual level. Consequently, a hyperketonemia testing protocol should provide a valid overview of variations within herd or group prevalence, as well as frequent information about cows affected, while limiting efforts and labor. The different testing scenarios we calculated provide a set of test characteristics for certain practical approaches. We found that the smaller the examination interval, the better the test characteristics. As the significance of a single positive test result during the whole observation period is unclear, as described above, the different gold-standard definitions (Table 3) allow a producer to choose whether cows with only 1 positive test result should be considered truly diseased and require treatment or not. With the presented scenarios and the given definitions of hyperketonemia, it is possible to choose a protocol that limits the proportion of false-positive or false-negative findings. It is obvious that a higher examination frequency results in higher sensitivity, allowing the producer to utilize a treatment 
Table 3. Test characteristics ${ }^{1}$ of different testing scenarios ${ }^{2}$ for the diagnosis of hyperketonemia in dairy cows during the first 6 weeks of lactation

\begin{tabular}{|c|c|c|c|c|c|}
\hline Gold standard & $\begin{array}{l}\text { Testing } \\
\text { scenario }\end{array}$ & $\begin{array}{c}\text { Se (\%) } \\
(95 \% \text { CI })\end{array}$ & $\begin{array}{c}\mathrm{Sp}(\%) \\
(95 \% \mathrm{CI})\end{array}$ & $\begin{array}{l}+\mathrm{PV}(\%) \\
(95 \% \text { CI })\end{array}$ & $\begin{array}{l}-\mathrm{PV}(\%) \\
(95 \% \mathrm{CI})\end{array}$ \\
\hline \multirow[t]{3}{*}{$\mathrm{BHBA} \geq 1.2 \mathrm{mmol} / \mathrm{L}$ at least once from 1 to $42 \mathrm{DIM}$} & G1T1 & $21(16-27)$ & 100 & 100 & $53(51-55)$ \\
\hline & G1T2 & $36(29-43)$ & 100 & 100 & $58(55-61)$ \\
\hline & G1T6 & $72(65-79)$ & 100 & 100 & $76(72-80)$ \\
\hline \multirow{2}{*}{$\mathrm{BHBA} \geq 1.2 \mathrm{mmol} / \mathrm{L}$ at least twice from 1 to $42 \mathrm{DIM}$} & G2T1 & $33(23-43)$ & $97(93-100)$ & $83(70-97)$ & $78(75-83)$ \\
\hline & G2T2 & $55(46-64)$ & $95(92-98)$ & $82(73-91)$ & $84(82-87)$ \\
\hline
\end{tabular}

${ }^{1} \mathrm{Se}=$ sensitivity, $\mathrm{Sp}=$ specificity, $+\mathrm{PV}=$ positive predictive value, $-\mathrm{PV}=$ negative predictive value.

${ }^{2}$ Testing scenarios G1T1 and G2T1 = testing all cows once between 1 and 42 DIM; testing scenarios G1T2 and G2T2 = testing all cows twice, once between 1 and 21 DIM and once between 22 and 42 DIM; testing scenarios G1T3 and G2T3 = testing all cows 3 times, once between 1 and 14 DIM, once between 15 and 28 DIM, and once between 29 and 42 DIM; testing scenarios G1T6 and G2T6 = testing all cows 6 times, once between 1 and 7 DIM, once between 8 and 14 DIM, once between 15 and 21 DIM, once between 22 and 28 DIM, once between 29 and 35 DIM, and once between 36 and 42 DIM.

benefit for more individual cows. A lower examination frequency reduces the workload but has an increased risk of underdiagnosing hyperketonemia and foregoing treatment benefits. Ospina et al. (2013) developed 3 different testing strategies, depending on the initial hyperketonemia prevalence estimated from testing a subset of at least 20 cows between 3 and 14 DIM. If estimated prevalence does not exceed $15 \%$, the authors recommend weekly sampling intervals. In herds with a hyperketonemia prevalence of 16 to $40 \%$, cows between 3 to 9 DIM should be tested twice weekly and cows thereby diagnosed as positive (BHBA $\geq 1.2 \mathrm{mmol} / \mathrm{L}$ ) should be treated with propylene glycol for $5 \mathrm{~d}$. If estimated prevalence exceeds 40\%, Ospina et al. (2013) recommend treating every cow with propylene glycol for $5 \mathrm{~d}$ without testing, starting at 3 DIM. These testing and treatment strategies are well defined, which facilitates their implementation in fresh cow protocols. In their assumption, however, cows are monitored only until 14 DIM. A common recommendation is to test cows for hyperketonemia during the first $2 \mathrm{wk}$ of lactation (Geishauser et al., 2001; LeBlanc, 2010; Ospina et al., 2013). Our data, however, provide evidence that a considerable proportion (47\%) of cows affected by hyperketonemia had the first positive BHBA test later and that the risk period for hyperketonemia lasts at least until 42 DIM. Therefore, we recommend screening protocols that include the first $6 \mathrm{wk}$ of lactation. Further research is needed to examine the occurrence of hyperketonemia in dairy cows after 42 DIM and, as previous research on the effect of hyperketonemia mostly observed cases diagnosed during the first 1 to 3 wk of lactation (LeBlanc et al., 2005; Duffield et al., 2009; Chapinal et al., 2011; Roberts et al., 2012), on the effect of hyperketonemia in later weeks of lactation. In particular, studies are warranted to verify current herd alarm levels for use in extended-duration hyperketonemia screening protocols.

\section{Study Limitations}

Our objective was to characterize the natural occurrence of hyperketonemia in dairy cows. Therefore, we tried to minimize external factors that could influence metabolic conditions such as medical treatments. However, different farms were monitored during this study, implying the existence of different management strategies and feeding programs for transition cows, planned and conducted by the farms' personnel, nutrition consultants, and veterinarians.

On farm 1, cows were offered an oral nutritional supplement containing dextrose immediately after parturition. However, most of the glucose requirements in ruminants are met by hepatic gluconeogenesis, and carbohydrate resorption from the gut is limited due to rumen digestion (Herdt, 2000; Drackley et al., 2001). Cows in the third or greater lactation additionally received a prophylactic treatment containing an injection of dexamethasone $(0.04 \mathrm{mg} / \mathrm{kg}$ of BW) administered at 0 DIM. Effects of glucocorticoids such as dexamethasone as prophylaxis and therapy for hyperketonemia have been summarized as equivocal (Gordon et al., 2013).

On farm 2, cows in the third or greater lactation received an intravenous bolus injection containing dextrose (160 g per cow) shortly after parturition at 0 DIM. Wagner and Schimek (2010) found that a one-time intravenous bolus administration of $50 \%$ dextrose solution in postpartum dairy cows was unlikely to prevent or resolve hyperketonemia. Suppression of blood BHBA concentrations lasted for less than $12 \mathrm{~h}$. As cows were not sampled before 1 DIM during our study, effects of 
oral and intravenous dextrose administration were considered negligible. On farms 1 and 2, cows were delivered a TMR containing 300 to $400 \mathrm{~g}$ of glycerol per cow and day. Lomander et al. (2012) did not find effects on BHBA concentration in early-lactation dairy cows fed concentrates supplemented with $450 \mathrm{~g}$ of glycerol. On farm 3, TMR was enriched by $300 \mathrm{~g}$ of propylene glycol per cow and day during the first 21 DIM. Although positive effects of bolus administrations of propylene glycol on resolution and further outcomes of hyperketonemia are well documented (McArt et al., 2011, 2012b), effects of propylene glycol administered via propylene glycol enriched TMR or concentrates have been found contradictory (Hoedemaker et al., 2004; Lomander et al., 2012).

In contrast to farms 1 and 2 , where cows were fed 10 times daily, cows on farm 3 were fed only once daily and feed was pushed up 3 times per day. Blood samples were taken after feed had been delivered and at approximately the same time of the day for the whole examination period. However, in view of an increasing number of cows enrolled in the screening, duration of the farm visits and therefore variability of sampling time relative to feeding increased from $-1 \mathrm{~h}$ until +3 h. Although sampling time did not affect blood BHBA concentrations in continuously fed dairy cows (Mahrt et al., 2014a), Quiroz-Rocha et al. (2010) described effects in cows fed only once or twice daily. In their study, however, BHBA concentrations and proportions of cows with hyperketonemia $(\mathrm{BHBA} \geq 1,400 \mu \mathrm{mol} / \mathrm{L}$ ) were not significantly different between samples taken at $-1 \mathrm{~h}$ and $+4 \mathrm{~h}$ relative to the first daily feeding. Therefore, time of sample collection was considered negligible in our study population.

Farms monitored during this study implemented different feeding and disease prevention strategies. This is inevitable when conducting a study on multiple commercial dairy farms, as has been discussed previously (Heuwieser et al., 2010), and is comparable to the situation in the field. Because incidence and prevalence of hyperketonemia vary within and between farms with different feeding and management programs and concomitant diseases, testing strategies to efficiently identify cows with hyperketonemia are necessary regardless of the farm's current incidence and prevalence.

\section{CONCLUSIONS}

The period in which early-lactation dairy cows are at risk for hyperketonemia lasts at least until 42 DIM. During this study, $47 \%$ of the cows affected by hyperketonemia had their first positive test later than 14 DIM. Testing cows at intervals of 2 wk during the first 42 DIM identified hyperketonemia with a sensitivity of
49 to $69 \%$ and a specificity of 91 to $100 \%$, regardless of the farm's incidence and prevalence of hyperketonemia. Weekly testing led to a sensitivity of 72 to $91 \%$ and a specificity of 83 to $100 \%$. Further research is required to determine the effects of time of occurrence and duration of hyperketonemia on subsequent disease, milk yield, and reproductive performance.

\section{ACKNOWLEDGMENTS}

The authors thank the owners, the herdswomen and herdsmen, and the staff of the participating farms.

\section{REFERENCES}

Andersson, L. 1988. Subclinical ketosis in dairy cows. Vet. Clin. North Am. Food Anim. Pract. 4:233-251.

Chapinal, N., M. Carson, T. F. Duffield, M. Capel, S. Godden, M. Overton, J. E. P. Santos, and S. J. LeBlanc. 2011. The association of serum metabolites with clinical disease during the transition period. J. Dairy Sci. 94:4897-4903.

Denis-Robichaud, J., J. Dubuc, D. Lefebvre, and L. DesCôteaux. 2014. Accuracy of milk ketone bodies from flow-injection analysis for the diagnosis of hyperketonemia in dairy cows. J. Dairy Sci. 97:3364-3370.

Dohoo, I. R., and S. W. Martin. 1984. Subclinical ketosis: Prevalence and associations with production and disease. Can. J. Comp. Med. 48:1-5.

Drackley, J. K., T. R. Overton, and G. N. Douglas. 2001. Adaptations of glucose and long-chain fatty acid metabolism in liver of dairy cows during the periparturient period. J. Dairy Sci. 84(ESuppl.):E100-E112.

Duffield, T. 2000. Subclinical ketosis in lactating dairy cattle. Vet. Clin. North Am. Food Anim. Pract. 16:231-253.

Duffield, T. F., K. D. Lissemore, B. W. McBride, and K. E. Leslie. 2009. Impact of hyperketonemia in early lactation dairy cows on health and production. J. Dairy Sci. 92:571-580.

Duffield, T. F., D. Sandals, K. E. Leslie, K. Lissemore, B. W. McBride, J. H. Lumsden, P. Dick, and R. Bagg. 1998. Efficacy of monensin for the prevention of subclinical ketosis in lactating dairy cows. J. Dairy Sci. 81:2866-2873.

Enjalbert, F., M. C. Nicot, C. Bayourthe, and R. Moncoulon. 2001. Ketone bodies in milk and blood of dairy cows: Relationship between concentrations and utilization for detection of subclinical ketosis. J. Dairy Sci. 84:583-589.

Geishauser, T., K. Leslie, D. Kelton, and T. Duffield. 2001. Monitoring for subclinical ketosis in dairy herds. Comp. Contin. Educ. Vet. 23:65-71.

Gordon, J. L., S. J. LeBlanc, and T. F. Duffield. 2013. Ketosis treatment in lactating dairy cattle. Vet. Clin. North Am. Food Anim. Pract. 29:433-445.

Herdt, T. H. 2000. Ruminant adaptation to negative energy balance. Influences on the etiology of ketosis and fatty liver. Vet. Clin. North Am. Food Anim. Pract. 16:215-230.

Heuwieser, W., M. Iwersen, J. Gossellin, and M. Drillich. 2010. Short communication: Survey of fresh cow management practices of dairy cattle on small and large commercial farms. J. Dairy Sci. 93:1065-1068.

Hoedemaker, M., D. Prange, H. Zerbe, J. Frank, A. Daxenberger, and H. H. D. Meyer. 2004. Peripartal propylene glycol supplementation and metabolism, animal health, fertility, and production in dairy cows. J. Dairy Sci. 87:2136-2145.

Holtenius, P., and K. Holtenius. 1996. New aspects of ketone bodies in energy metabolism of dairy cows: A review. Zentralbl. Veterinarmed. A 43:579-587.

Ingvartsen, K. L. 2006. Feeding- and management-related diseases in the transition cow. Physiological adaptations around calving 
and strategies to reduce feeding-related diseases. Anim. Feed Sci. Technol. 126:175-213.

Iwersen, M., U. Falkenberg, R. Voigtsberger, D. Forderung, and W. Heuwieser. 2009. Evaluation of an electronic cowside test to detect subclinical ketosis in dairy cows. J. Dairy Sci. 92:2618-2624.

Iwersen, M., D. Klein-Jöbstl, M. Pichler, L. Roland, B. Fidlschuster, I. Schwendenwein, and M. Drillich. 2013. Comparison of 2 electronic cowside tests to detect subclinical ketosis in dairy cows and the influence of the temperature and type of blood sample on the test results. J. Dairy Sci. 96:7719-7730.

LeBlanc, S. 2010. Monitoring metabolic health of dairy cattle in the transition period. J. Reprod. Dev. 56(Suppl.):S29-S35.

LeBlanc, S. J., K. E. Leslie, and T. F. Duffield. 2005. Metabolic predictors of displaced abomasum in dairy cattle. J. Dairy Sci. 88:159-170.

Lomander, H., J. Frössling, K. L. Ingvartsen, H. Gustafsson, and C. Svensson. 2012. Supplemental feeding with glycerol or propylene glycol of dairy cows in early lactation - Effects on metabolic status, body condition, and milk yield. J. Dairy Sci. 95:2397-2408.

Mahrt, A., O. Burfeind, and W. Heuwieser. 2014a. Effects of time and sampling location on concentrations of $\beta$-hydroxybutyric acid in dairy cows. J. Dairy Sci. 97:291-298.

Mahrt, A., O. Burfeind, R. Voigtsberger, A. Müller, and W. Heuwieser. 2014b. Evaluation eines neuen elektronischen Handmessgeräts zur Messung von $\beta$-Hydroxybutyrat bei Milchkühen. Tierarztl. Prax. Ausg. G Grosstiere Nutztiere 42:5-10.

McArt, J. A. A., D. V. Nydam, and G. R. Oetzel. 2012a. Epidemiology of subclinical ketosis in early lactation dairy cattle. J. Dairy Sci. 95:5056-5066.

McArt, J. A. A., D. V. Nydam, and G. R. Oetzel. 2012b. A field trial on the effect of propylene glycol on displaced abomasum, removal from herd, and reproduction in fresh cows diagnosed with subclinical ketosis. J. Dairy Sci. 95:2505-2512.

McArt, J. A. A., D. V. Nydam, G. R. Oetzel, T. R. Overton, and P. A. Ospina. 2013. Elevated non-esterified fatty acids and $\beta$-hydroxybutyrate and their association with transition dairy cow performance. Vet. J. 198:560-570.

McArt, J. A. A., D. V. Nydam, P. A. Ospina, and G. R. Oetzel. 2011. A field trial on the effect of propylene glycol on milk yield and resolution of ketosis in fresh cows diagnosed with subclinical ketosis. J. Dairy Sci. 94:6011-6020.

Oetzel, G. R. 2004. Monitoring and testing dairy herds for metabolic disease. Vet. Clin. North Am. Food Anim. Pract. 20:651-674.

Oetzel, G. R. 2007. Herd-level ketosis-Diagnosis and risk factors. Pages 67-91 in Proc. 40th Annu. Conf. Am. Assoc. Bovine Pract., Vancouver, Canada. Am. Assoc. Bovine Pract., Auburn, AL

Ospina, P. A., J. A. McArt, T. R. Overton, T. Stokol, and D. V. Nydam. 2013. Using nonesterified fatty acids and $\beta$-hydroxybutyrate concentrations during the transition period for herd-level monitoring of increased risk of disease and decreased reproductive and milking performance. Vet. Clin. North Am. Food Anim. Pract. 29:387-412.

Ospina, P. A., D. V. Nydam, T. Stokol, and T. R. Overton. 2010. Association between the proportion of sampled transition cows with increased nonesterified fatty acids and $\beta$-hydroxybutyrate and disease incidence, pregnancy rate, and milk production at the herd level. J. Dairy Sci. 93:3595-3601.

Quiroz-Rocha, G. F., S. J. LeBlanc, T. F. Duffield, B. Jefferson, D. Wood, K. E. Leslie, and R. M. Jacobs. 2010. Short communication: Effect of sampling time relative to the first daily feeding on interpretation of serum fatty acid and $\beta$-hydroxybutyrate concentrations in dairy cattle. J. Dairy Sci. 93:2030-2033.

Roberts, T., N. Chapinal, S. J. LeBlanc, D. F. Kelton, J. Dubuc, and T. F. Duffield. 2012. Metabolic parameters in transition cows as indicators for early-lactation culling risk. J. Dairy Sci. 95:30573063.

Roche, J. R., N. C. Friggens, J. K. Kay, M. W. Fisher, K. J. Stafford, and D. P. Berry. 2009. Invited review: Body condition score and its association with dairy cow productivity, health, and welfare. J. Dairy Sci. 92:5769-5801.

Shire, J., J. L. Gordon, and E. L. Karcher. 2013. Short communication: The effect of temperature on performance of milk ketone test strips. J. Dairy Sci. 96:1677-1680.

Suthar, V. S., J. Canelas-Raposo, A. Deniz, and W. Heuwieser. 2013. Prevalence of subclinical ketosis and relationships with postpartum diseases in European dairy cows. J. Dairy Sci. 96:2925-2938.

van der Drift, S. G. A., K. J. E. van Hulzen, T. G. Teweldemedhn, R. Jorritsma, M. Nielen, and H. C. M. Heuven. 2012. Genetic and nongenetic variation in plasma and milk $\beta$-hydroxybutyrate and milk acetone concentrations of early-lactation dairy cows. J. Dairy Sci. 95:6781-6787.

Wagner, S. A., and D. E. Schimek. 2010. Evaluation of the effect of bolus administration of $50 \%$ dextrose solution on measures of electrolyte and energy balance in postpartum dairy cows. Am. J. Vet. Res. 71:1074-1080.

Walsh, R. B., D. F. Kelton, T. F. Duffield, K. E. Leslie, J. S. Walton, and S. J. LeBlanc. 2007a. Prevalence and risk factors for postpartum anovulatory condition in dairy cows. J. Dairy Sci. 90:315-324.

Walsh, R. B., J. S. Walton, D. F. Kelton, S. J. LeBlanc, K. E. Leslie, and T. F. Duffield. 2007b. The effect of subclinical ketosis in early lactation on reproductive performance of postpartum dairy cows. J. Dairy Sci. 90:2788-2796. 